\title{
Gaming
}

\section{War Hawks and Peace Doves: alternate resolutions of experimental conflicts}

\author{
MARC PILISUK, PAUL POTTER, ANATOL RAPOPORT, and J. ALAN WINTER ${ }^{1}$ \\ Mental Health Research Institute, The University of Michigan
}

The two-person, two-choice Prisoner's Dilemma game offers the players an opportunity to demonstrate either trust, by choosing the cooperative (C) response, or suspicion, by choosing the defection (D) response (Deutsch, 1958). In the conventional experimental situation each of the players has an opportunity to make only the completely cooperative response or the completely defecting response. Cooperative responses when made by both players provide rewards to both. Defecting responses, if they are mutual, are detrimental to both players. The incentive to defect, however, derives from the nature of payoffs following asym-

\footnotetext{
${ }^{1}$ Research relating to this project was made possible by assistance from the following sources: National Science Foundation, grants G 99 and GS 586; National Institutes of Health, M-423801-02-03-04-05; and Sigma Xi, the Scientific Research Society of America. Marc Pilisuk is now with the Department of Psychology and the Krannert Graduate School, Purdue University; Paul Potter is now with the Economic Research and Action Projects of the Students for a Democratic Society; J. Alan Winter is now with the Department of Sociology, Rutgers University.
}

metrical choices by the pair members. When one player defects (chooses D) unilaterally while the second player chooses $C$, the defector is most highly rewarded and to the detriment of the cooperator. When the game is played without communication, rationality (in the strict sense of game theory) provides no solution consistent with the collective interests of the players.

The following example of a payoff matrix for a Prisoner's Dilemma game helps to demonstrate the nature of the dilemma:

$$
\begin{array}{ccc}
\text { Player A's } & \text { Choices } \\
\text { C } & \text { D }
\end{array}
$$

$\begin{array}{llrc}\text { Player B's } & \text { C } & 20,20 & 40,-20 \\ \text { Choices } & \text { D } & -20,40 & 0,0\end{array}$

In repeated trials of a game of this kind, a pair of players generally establishes a stable relationship. This relationship is characterized either by a lengthy succession of mutually beneficial outcomes (CC) or by a succession of mutually punishing or nonrewarding outcomes (DD). There are, of course, trials in which only one player tries to cooperate while his partner defects and 
gains at his expense. But the frequency of such asymmetrical behavior declines after a series of trials and pairs generally fall into either the cooperative pattern or the noncooperative, from which they depart only rarely (Rapoport, 1965; Pilisuk and Rapoport, 1963). The significance of this lock-in phenomenon lies in the degree to which the game presents a microsimulation of interpersonal behavior. Two individuals are obliged to make a series of behaviors which affect their partner's well-being as well as their own. Eventually, large numbers of these pairs develop a stable interaction pattern which defines them as a social unit.

What characteristics distinguish a cooperating pair of "Peace Doves" from a competing pair of "War Hawks"? Are their personalities different? Are the Doves in a pair more like each other than the members of Hawk pairs? Does the game environment, aside from such obvious experimental manipulation as changing the payoff matrix, affect the relative frequencies of Dove-like or Hawk-like outcomes? And, perhaps of greatest importance to the psychologist, is there a pattern of early play, a system of gestures and responses in the game itself, which so teaches the lesson of cooperation that it is productive of Doves rather than of Hawks?

The game designed to answer these questions is more complex than the two-choice game described previously. The new form permits each player a range of moves in every trial of the game so that his choice is no longer constricted to total cooperation or total defection but may vary from 0 to 20 units of cooperation, as may his partner's choice. The resultant 21 by 21 matrix of possible outcomes is so fixed as to contain the same basic paradox as the 2 by 2 game. Like the 2 by 2 game, the newer design produces its quota of Dove pairs, Hawk pairs, and some intermediary ("Mugwump") pairs.

The difference is that the newer game more closely approximates many actual situations where the choice is not whether to cooperate or not but rather what degree of cooperation to choose. Also, a versatile set of arms-race-simulating conditions, e.g., missile conversion, inspection, etc., are easily fitted to the game (Pilisuk and Rapoport, 1964). And most important, the added choice flexibility permits a more refined study of gestures and responses which may lead players to suspicion or to trust.

\section{Method}

A total of 128 male college students (64 pairs) participated as subjects in this study. The experimental room contained booths permitting up to three pairs of subjects to participate simultaneously while completely eliminating visual and verbal contact between pair members. Subjects who knew one another prior to the experimental session were not paired. Recruitment was from volunteers for paid psychological experiments.

Subjects first completed questionnaires used to assess self-acceptance and monetary risk performance. The characteristics of the game were then described to them and play began. Upon completion of games a brief strategy questionnaire was used to obtain subjective descriptions of strategies employed. After the experimental session was completed, subjects were asked to take home and complete the questionnaires which were used to assess tolerance for ambiguity, internationalism, and social risk preference. Upon receipt of completed take-home questionnaires, subjects were paid for their participation in the experiment, in amounts 
corresponding to their actual achievements in the game. ${ }^{2}$

When play began, the player sat facing an $8^{\prime \prime} \times 10^{\prime \prime}$ playing board divided into 20 squares. A two-faced poker chip, white on one side, blue on the other, was on each square. All twenty chips were placed white side up at the start. Each player was also given a full matrix of outcomes showing the payoff to each player for every possible combination of choices by himself and by the other player. (A representation of this matrix, reduced to $5 \times 5$, is presented in Figure 1.) A play consisted of turning any number of discs (from 0 to 20 ) from white to blue.

The payoffs may be understood as reward-

2 The tolerance for ambiguity measure is a six-point Likert-type scale containing the eighteen items relating to preferences for regularity or change, clarity or ambiguity, balance or asymmetry, etc. Nine items were selected from a pool of $\mathbf{F}$ scale correlate items which had been classified by their authors as measures of tolerance for ambiguity (Webster et al., 1955). The remaining nine items were taken from a measure of tolerance for ambiguity reported in a study by O'Connor (1952). The F scale has been shown to predict noncooperation in simple non-zero-sum games. The authors suspected the "cognitive style" aspect of authoritarianism to be more relevant to game performance than the affective or attitudinal components and selected tolerance for ambiguity for measurement.

The self-acceptance measure was included in the battery to test the notion that acceptance of oneself might be instrumental to the development of trust for a partner. People who are less self-accepting tend also to be less accepting of others (Berger, 1952) and, perhaps, less willing to trust the other player in a non-zero-sum game. Fifty items were selected randomly, onehalf of all those used in the Q-sort technique reported in Rogers and Dymond (1954). Actual discrepancies between self-image and ideal image were used.

The internationalism scale contained items from other attitude scales (Levinson, 1957; ing each player one unit ( 2 monetary mills) for each blue side he exposes. If both players expose an identical number of blue tokens their payoffs are completely determined by this number. In the event of a disparity between the players in the number of blue chips exposed, the player showing fewer blue chips is given an additional payoff equal to twice the size of the disparity. For the player showing the larger number of blue tokens an amount equal to twice the disparity is subtracted from his total payoff. If players $A$ and $B$ expose $\mathrm{Bl}_{\mathrm{a}}$ and $\mathrm{Bl}_{\mathrm{b}}$ blue chips respectively and receive payoffs $P_{a}$ and $P_{b}$ respectively, then (1) $P_{a}=2 \mathrm{Bl}_{b}-$ $\mathrm{Bl}_{\mathrm{a}}$ and (2) $\mathrm{P}_{\mathrm{b}}=2 \mathrm{Bl}_{\mathrm{a}}-\mathrm{Bl}_{\mathrm{b}}$.

In other words, conversion to blue chips is rewarding when mutual but punishing to the degree that it is unilateral. Conversely, retention of white chips is nonrewarding if mutual, but rewarding to the extent that it is unilateral. Specifically: (1) if both play-

Samson and Smith, 1957) combined and modified to produce a set of questions which the authors felt might be appropriate for the population at hand. (Copies of the scale are available on request.) Because internationalism was shown to be related to non-zero-sum game behavior (Lutzker, 1960), we anticipated an even greater effect upon game behavior in games loaded with the semantic referents of the arms race.

Since monetary rewards were used in the game we felt that the individual's propensity to take risks might affect his play. Two measures were used to assess an individual's propensity to take risks. The first, a gambling task involving real monetary rewards, was followed by a task of social risk preference.

The monetary risk preference measure consists of a set of choices among actual monetary gambles which subjects make. (Copies are available.) The measure of social risk-taking was reported by Kogan and Wallach (1961). It investigates the chances which people would be willing to take in a series of life-like social situations. 


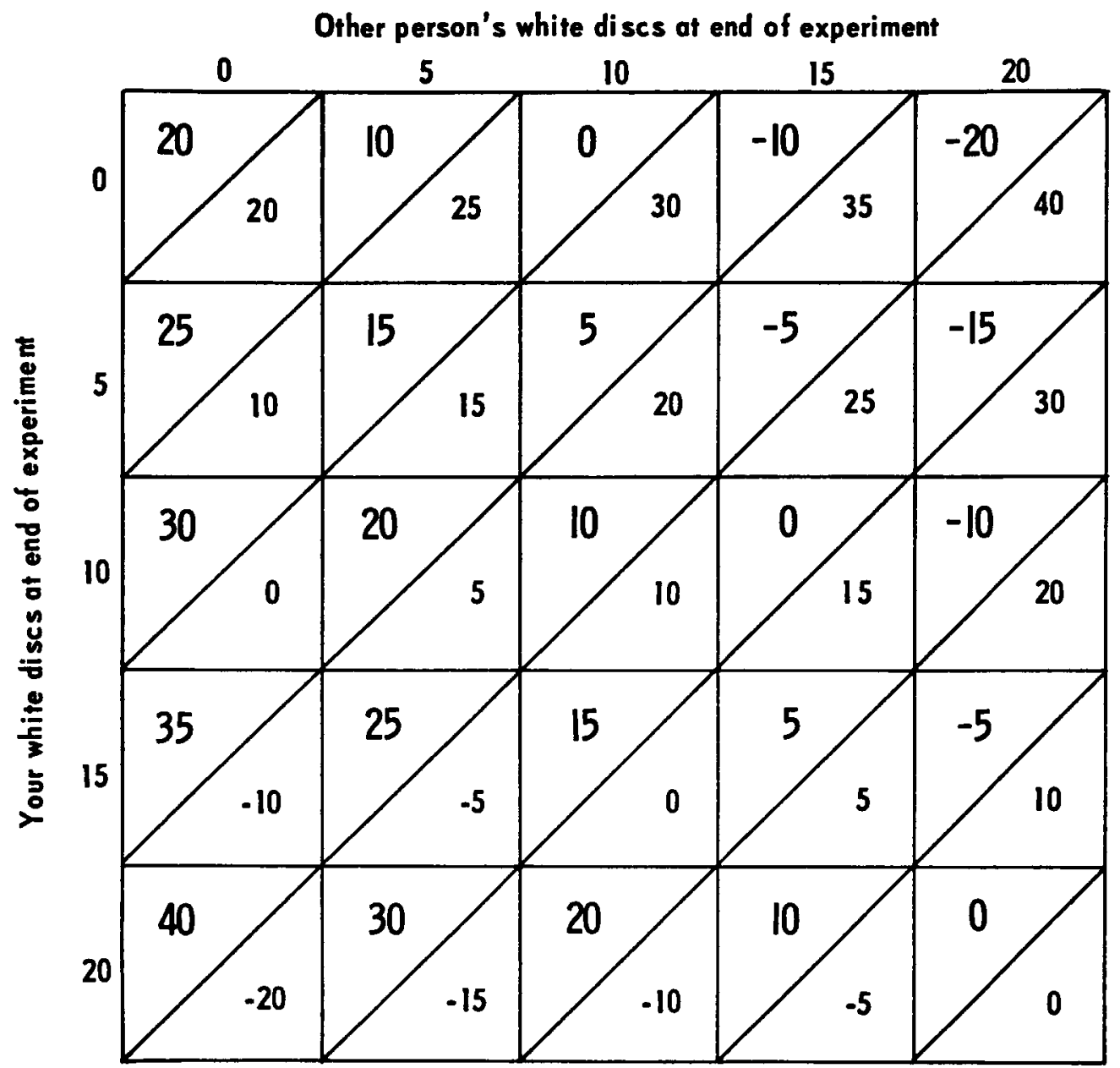

Fic. 1. Reduced form of payoff matrix shown to players. The actual matrix used showed all values from 0 to 20 . The first figure in each box represents one's own payoff; the second figure, the payoff for the other player.

ers convert fully from white to blue chips, both win 20 units; (2) if neither player converts any tokens to their blue side, neither receives any units; (3) complete unilateral conversion to blue matched against an opposing player's complete retention of white results in a loss of 20 units to the cooperator and a gain of 40 units to the defector; and (4) payoffs between these extremes are determined by both the number of blue chips one exposes and the difference between that number and the number exposed by the other player. The extreme outcomes are identical to those shown in the illustrative two-choice payoff matrix given earlier. Some intermediate outcomes appear in Figure 1.

The game was played in two experimental settings, the abstract and the simulated. Sixty-four players, one-half the total, played only abstract games. The other half played 
simulated games exclusively. The abstract game has already been described. In it the tokens on the game board are merely tokens, i.e., poker chips which were blue on one side and white on the other. Instructions avoided such evaluative words as "cooperation or competition," "winning or losing," "contest," "opponent," and even "game." While these words were also omitted in the simulated condition, a new set of evaluative symbols was used. The simulated game was introduced with the terminology of an armsrace-disarmament dilemma. A token with its white side showing was referred to as a weapon and contained a schematic picture of a missile upon it. Blue-side-up tokens were called economic units and contained schematic pictures of factories. A game board was a country. The simulated condition was intended to heighten the game's similarity to the arms race without expressing preference for either armament or disarmament.

Payoffs were identical in abstract and simulated conditions. After each play of the 55 plays of the game, a player was informed of his partner's choice by receipt of a note from the experimenter. From this he could refer to his matrix and keep informed of his payoffs.

The second experimental variation involved the manner in which players made their decision as to how far to cooperate or disarm, i.e., how many tokens to turn from white to blue. In the short game which has already been described, each player makes a single move converting from zero to twenty of his tokens. The single moves by the two players determine the payoffs to each and terminate that trial or play of the game.

The long game consisted of twenty separate moves. On a given move, white chips could be converted to blue, or blue chips could be converted back to white, provided only that a player might never turn more than two chips on any given move. No feedback was given prior to the twentieth (last) move. Since the intermediate moves of each player had no effect upon payoffs and were not made known to the other participant, the long game appears identical with the short. In fact, the long and short games are logically isomorphic. However, they may differ psychologically. Forcing players to enact their final decision in gradual steps could alter the decision.

All subjects played 40 short and 15 long games. Half of the subjects began with 40 short games and then played 15 long games. The other half reversed this order. A block design of the experimental variation is shown here:

$\begin{array}{lcc} & \text { Abstract } & \text { Simulated } \\ \text { Long First } & \mathrm{A}_{1} & \mathrm{~S}_{1} \\ \text { Short First } & \mathrm{A}_{2} & \mathrm{~S}_{2}\end{array}$

\section{Results ${ }^{3}$}

A. SELECTION OF CRITERION PATRS

The data deal with characteristics of three types of pairs. The pairs were classified into discrete categories in accordance with the performance of both players during the last five games in an experimental session containing 55 games. The pair labels are Dove (cooperators), Hawk (noncooperators), and Mugwump (intermediate). A pair was labeled Dove if (1) both players turned 15 or more of their tokens from white to blue during each one of the last

\footnotetext{
${ }^{3}$ Results contained here deal exclusively with the differentiation between criterion groups designated by performance during the last five plays of the game. The effects of experimental conditions on such gross indices of behavior as the average number of tokens turned over in all trials are discussed in Pilisuk and Rapoport (1963).
} 
five games and (2) neither player turned over fewer than 17 tokens per trial, on an average, over these same trials. The Hawk criteria are completely symmetrical. A Hawk pair was so designated where (1) neither player turned more than 5 tokens to their blue side during the last five trials and (2) neither player turned over an average of three tokens or more per trial during these same games. The third and intermediate group, Mugwumps, contains all the remaining pairs which failed to meet the conditions for classification as either Dove or Hawk.

The grouping provides 26 pairs of Doves, 17 pairs of Hawks, and 21 Mugwump pairs. These criterion groups were used for the remainder of the analysis. The groupings, while arbitrary, provide for stringent differentiation between the cooperators (Doves) and the noncooperators (Hawks). (The probability that two players, making random choices, will fall into one of these two groups is less than $10^{-5}$.) Some Mugwump pairs, however, were apparently moving toward greater cooperation during the final five trials and might have met the Dove criterion had the experiment continued beyond 55 trials. Some Mugwumps, on the other hand, were showing essentially noncooperative behavior but not quite to the Hawk criterion. Even among the more homogeneous Dove and Hawk groups, pair histories display some interesting differences as well as similarities. For example, by applying the five-trial block criterion to trials earlier than the last five it is possible to split the Dove pairs into early and later cooperators. And it is possible to identify, among both Hawks and Doves, some few pairs who met the criterion and then lost it. By the end of an hour and a half of game play, however, the Doves were locked into the pattern of mutual cooperation, the Hawks were locked into a conflict of dis- trust, and the Mugwumps had achieved neither of these stable patterns.

\section{B. THE INFLUENCE OF PERSONALITY VARIABLES}

Five personality variables were assessed. They were: (1) self-acceptance; (2) monetary risk preference; (3) tolerance for ambiguity; (4) internationalism; and (5) social risk preference. A brief rationale for the selection of these variables has been given in footnote 2.

We asked two questions about the differences in the personalities of the Doves, Hawks, and Mugwumps. First, we asked: Do the individual Doves, Hawks, and Mugwumps differ on the dimensions of personality we thought relevant to game behavior? That is, is the average Dove (or Hawk or Mugwump) different from members of the other two groups? Second, we asked: Do pair members among Dove, Hawk, or Mugwump pairs differ in the extent to which they are similar to their partners? The import of the second question may be seen in two variants of it. Do members of a pair of Doves resemble one another more closely or less closely than members of a typical Hawk or Mugwump pair? And does the instability of the Mugwumps' resolution reflect a greater personality disparity between partners than might be found among either Doves or Hawks?

Mean scores on each of the five individual difference measures are contrasted for Doves, Hawks, and Mugwumps in Table 1.

Examination of the differences between means on each variable presents a consistent and negative picture. The $F$ values are not statistically significant. The variables selected here do not predict well to criterion group performance. With the possible exception of tolerance for ambiguity, which may favor the potential for achievement of 
TABLE 1

Personaltit Differences Among Doves, Hawks, and Mugwumps

\begin{tabular}{lrrrrr}
\hline \hline \multirow{1}{*}{\multicolumn{1}{c}{$\begin{array}{c}\text { Personality } \\
\text { Measures }\end{array}$}} & \multicolumn{3}{c}{ MEANs } & \multirow{2}{*}{ F $_{2 / 127}$} & p \\
\cline { 2 - 4 } & \multicolumn{1}{c}{ Doves } & Hawks & Mugwumps & & \\
\hline Self-acceptance & 1.885 & 1.545 & 2.007 & 0.03 & NS \\
Tolerance for Ambiguity $^{\mathbf{b}}$ & -10.038 & -3.618 & -3.929 & 0.003 & NS \\
Internationalism & 21.558 & 25.235 & 24.262 & 0.01 & NS \\
Monetary Risk Preference & 45.154 & 47.029 & 45.905 & 0.003 & NS \\
Social Risk Preference & 45.250 & 45.353 & $\mathbf{4 3 . 6 1 9}$ & 0.003 & NS \\
\hline
\end{tabular}

a Low scores indicate greater self-acceptance.

b Low scores indicate greater tolerance for ambiguity.

the Dove group criterion, there is little even to suggest that personality characteristics might be exerting a noticeable influence. This may appear in some contrast to the work of Deutsch (1960b) and Lutzker (1960) in the simpler two-choice games, but it must be recalled that they used total cooperation by an individual over all trials of a game. ${ }^{4}$ Here, in addition to using a more complex game, the prediction is to the terminal behavior of the pair of players. ${ }^{5}$ One negative finding which calls for special note is that internationalism scores did not predict significantly to criterion groups, even for those experimental groups playing under the simulated arms-race-disarmament condition. One highly internationalistic subject, an active advocate of disarmament and other liberal causes, displayed game be-

${ }^{4}$ Actually the experimental situations are not strictly comparable. Deutsch predicted to the Prisoner's Dilemma game played once. Lutzker's payoff matrix presents the subject with an essentially different problem-the game of "chicken" rather than the Prisoner's Dilemma game. The two games are related, but in "chicken" unilateral cooperation is more rewarding than mutual defection and the motives for noncooperation are thus altered. The matrix shown on p. 491 above would be a "chicken" matrix if $(0,0)$ were changed to, say, $(-25,-25)$.

${ }^{5}$ Prediction from personality measures to gross levels of cooperation was only slightly more promising. No correlation as large as \pm 0.4 was found. havior which was filled with unpredictable treachery and rearmament, at his opponent's expense. His comments on this performance were that while he felt he ought to move toward disarmament he also felt, at the same time, the challenge of the game. The opportunity he perceived to make a killing was too great.

In one sense, it is not surprising that individual difference variables predict poorly to game outcomes. The very fact that Prisoner's Dilemma games so frequently result in "lock-ins" of either cooperation or noncooperation attests to the fact that randomly matched personalities do come to resemble one another in performance.

Such results suggest that individual personality has little effect on game behavior but do not rule out the possibility that personality characteristics of the pair, the match of traits between partners, may be effective. After all, the fact that diverse players come to resemble one another in game behavior does not explain why the resemblance is in cooperative (Dove-type) behavior in some cases and in much more competitive (Hawk-type) behavior in others. Similarity scores for a pair were obtained, using all personality measures in combination. Each measure was divided into thirds of high, medium, and low scores. When members of a pair both fell into the same third a score of 2 was entered, adjacent 
TABLE 2

Personality Smmilarity of Doves, Hawks, AND MUGWUMPs"

\begin{tabular}{|c|c|c|c|}
\hline & \multicolumn{2}{|c|}{ SIMILARITY } & \multirow[b]{2}{*}{$\mathrm{N}$} \\
\hline & $\begin{array}{l}\text { Low } \\
5 \text { or less }\end{array}$ & $\begin{array}{l}\text { High } \\
6 \text { or more }\end{array}$ & \\
\hline Doves & $50 \%(13)$ & $50 \%(13)$ & 26 \\
\hline Hawks & $41 \quad(7)$ & 59 (10) & 17 \\
\hline \multirow[t]{2}{*}{ Mugwumps } & (9) & $57 \quad(12)$ & 21 \\
\hline & $\overline{45} \quad \overline{(29)}$ & $\overline{55} \quad \overline{(35)}$ & $\overrightarrow{64}$ \\
\hline
\end{tabular}

" Entries are percentages over rows. Numbers in parenthesis are frequencies.

thirds were scored 1 , and extreme thirds were scored 0 . Summed over five variables this produced a possible range of similarity scores from 10 (very similar) to 0 (very dissimilar). Table 2 compares the more similar pairs (scores of 6 or more) with the less similar pairs (scores of $\mathbf{5}$ or less).

The data, again, show nothing of statistical significance and hardly anything in trends worthy of further examination. Refinement of similarity indices using actual numerical discrepancies and correcting for small intercorrelations among the separate measures would obviously contribute little to understanding why some pairs become Doves, others Hawks, and others Mugwumps.

One single personality variable seemed to offer better differentiation of criterion groups than did the five-test battery. Pair members who were both high on tolerance for ambiguity were more likely to become Doves than were pairs lower on this variable $(p<$ 0.01). Pair scores in tolerance for ambiguity are shown related to criterion groups in Table 3.

\section{THE INFLUENCE OF THE EXPERIMENTAL SETTING}

There were four experimental groups, as shown in the block design (see above, p. 495). Two groups, $A_{1}$ and $A_{2}$, played
TABLE 3

Comparuson of Dove Patrs High or Low on TOLERANCE FOR AMBIgUity WITH COMBINED Hawk and Mugwump PaIrS

\begin{tabular}{|c|c|c|c|c|}
\hline & \multicolumn{3}{|c|}{$\begin{array}{c}\text { PaIR RATING ON TOLERANCE } \\
\text { FOR AMBIGUITY }\end{array}$} & \multirow[b]{2}{*}{$\mathbf{N}$} \\
\hline & \multicolumn{2}{|c|}{$\begin{array}{l}\text { Hi-Hi or } \\
\text { Hi-Med }\end{array}$} & $\begin{array}{l}\text { Lo-Lo or } \\
\text { Lo-Med }\end{array}$ & \\
\hline Doves & \multicolumn{2}{|c|}{$68.5 \%$ (13) } & $31.5 \%(6)$ & (19) \\
\hline \multirow{2}{*}{$\begin{array}{l}\text { Hawks and } \\
\text { Mug- } \\
\text { wumps }\end{array}$} & 30.8 & (8) & $69.2(18)$ & (26) \\
\hline & 46.6 & (21) & $53.4(24)$ & $(45)$ \\
\hline
\end{tabular}

$\chi^{2}: 16.00 \quad \mathrm{p}<0.01$

Nore: Actual frequencies are given in parenthesis. $N$ for this table is 45 , i.e., 19 Dove pairs and 26 Hawk and Mugwump pairs. Pairs receiving Hi-Lo or Med-Med ratings are excluded from this analysis.

only abstract games. Groups $S_{1}$ and $S_{2}$ played only the simulated arms-race games. Groups $A_{1}$ and $S_{1}$ each started with fifteen long games followed by forty short games, whereas in groups $A_{2}$ and $S_{2}$ the forty short games came first. The number of pairs of Doves (cooperators), Hawks (defectors), and Mugwumps (in-betweens) in each of the four conditions is given in Table 4.

The findings in Table 4 can be summarized, but certain interactions between the effects of the two experimental conditions are difficult to interpret. A comparison of the conditions $A_{1}$ and $S_{1}$ (long first) with the $A_{2}$ and $S_{2}$ (short first) conditions in both the abstract and simulated forms would tend to indicate that playing the long game first produces more Doves relative to the proportion of Hawks and Mugwumps. This long-short difference tends, however, to be muted in the simulated $\left(S_{1}\right.$ and $\left.S_{2}\right)$ conditions. Hence, simulation makes the likelihood of becoming Doves or Mugwumps more nearly equal in the long-first and short-first conditions. However, the likelihood of becoming Hawks, while favored by the short-first conditions, shows this effect most markedly under simulated conditions. 
TABLE 4

The Effect of Expertmental Varuations on Formation of Cruteruon Groups

\begin{tabular}{|c|c|c|c|c|}
\hline & Doves & Hawks & Mugwumps & \\
\hline Abstract-Long First $\left(A_{1}\right)$ & $68.8 \%(11)$ & $25.0 \% \quad(4)$ & $6.2 \% \quad(1)$ & 16 \\
\hline Abstract-Short First $\left(A_{2}\right)$ & 12.5 & 31.2 & 56.2 & 16 \\
\hline Simulated-Long First $\left(\mathrm{S}_{1}\right)$ & 50.0 & 12.5 & 37.5 & 16 \\
\hline \multirow[t]{2}{*}{ Simulated-Short First $\left(\mathrm{S}_{2}\right)$} & 31.2 & 37.5 & 31.2 & $\underline{16}$ \\
\hline & $40.6 \quad(26)$ & $26.5 \quad(17)$ & $32.8 \quad(21)$ & $\overrightarrow{64}$ \\
\hline
\end{tabular}

$\chi^{2}$ (total) 15.22; $p<0.06$ (df: 2); $\chi^{2}$ (interaction) $5.77 ; p<0.05$ (df: 2 ).

Arms-race labels, then, seem to be of secondary import and seem not to exert independent effects upon criterion groups. The labels do, however, show some effects in interaction with the other experimental condition.

The apparent conduciveness of long-first conditions $A_{1}$ and $S_{1}$ to the production of cooperating Doves may be seen in Table 5, which contrasts all long-first games with all short-first games.

This comparison shows, rather clearly, that partners who started by playing the slower long games and then switched to the rapid short ones were quite likely to turn into cooperating Doves. Conversely, those who began with the rapid short games were more likely to turn into either the undistinguished Mugwumps or the uncooperative Hawks. Whether this distinction is a function of boredom and/or need for activity is not known. Certainly, in starting from a fully armed position, twenty separate opportunities to do something-in this case, to disarm-may be more difficult to resist than a single opportunity. Full control of this "mechanical" feature would require a reversal of the game with the initial level being the disarmed state. At this point, another hunch is that a cognitive reappraisal process quite apart from boredom is operating to induce cooperation (see discussion below).

When all players of abstract games are compared with all players in the arms-racesimulating games, the insignificance of simulation stands out clearly (see Table 6). Abstract games produce the same number of Doves, of Hawks, and of Mugwumps as do simulated games. In terms of final outcome for the pair, arms-race labels apparently make no difference.

One might argue that the absence of effects of the arms-race label should be expected, because the label does not affect the strategic structure of the game. However, the long and the short versions of the game are also strategically equivalent. Yet pronounced differences are observed in the two versions. Why? The authors suspect that something in the protracted nature of the long game permits more time for cognitive reappraisal of alternatives. Some yet unpublished results suggest that when the "player" is actually a team of three persons, a period of communication within the team (but not between teams) increases cooperation (Martin, 1964). Perhaps time favors such reappraisal by giving the individual player more chance to discuss alternatives with himself. Once begun, the rewards of the cooperative path tend to be reinforcing and self-perpetuating even if a switch is made to the short game.

\section{EARLY DIFFERENCES IN PLAY}

Criterion groups were distinguished, orig- 
TABLE 5

The Effect of Length of Initial 15 Games on Formation of Criterion Groups

\begin{tabular}{|c|c|c|c|c|}
\hline $\begin{array}{l} \\
\text { Long First }\left(\begin{array}{lll}A_{1} \& S_{1}\end{array}\right) \\
\text { Short First }\left(\begin{array}{lll}A_{2} & \& & S_{2}\end{array}\right)\end{array}$ & \multirow{2}{*}{$\frac{\text { Doves }}{59.4 \%(19)}$} & Hawks & Mugwumps & \multirow{3}{*}{$\begin{array}{l}32 \\
32\end{array}$} \\
\hline \multirow{3}{*}{$\begin{array}{l}\text { Long First }\left(\begin{array}{lll}A_{1} \& S_{1}\end{array}\right) \\
\text { Short First }\left(\begin{array}{lll}A_{2} & \& & S_{2}\end{array}\right)\end{array}$} & & $18.8 \%(6)$ & $21.9 \% \quad(7)$ & \\
\hline & 21.9 & $34.4 \quad$ (11) & $43.7 \quad(14)$ & \\
\hline & $31.2 \quad(26)$ & $26.5 \quad$ (17) & $32.8 \quad(21)$ & 64 \\
\hline
\end{tabular}

$\chi^{2}: 9.34 ; p<0.01$ (df: 2 ).

inally, by their performance on the last five of 55 consecutive games. Early experience in each of these criterion groups is defined by pair behavior during the first five games, in particular, but also by pair behavior in games six through ten.

Three measures of early game behavior were used: (1) cooperativeness, measured by the number of tokens turned from white to blue-the greater the number, the more cooperative; (2) cooperative gesture, defined as a play of the game in which a player converts 10 or more tokens, one-half or more of his total, from white to blue (in any given trial there may be a cooperative gesture by both, by one, or by neither player); (3) discrepant outcome, defined as a game in which one player converts five or more tokens from white to blue in excess of the number turned by his partner. The significance of discrepant outcomes, as a measure, is that they indicate an experience in which one player has gained at the other's expense. It means that one player on that trial was, unilaterally, cooperating more than his adversary. Over a period of five trials it is possible for both players to have both experiences-being at the short end and at the long end of the discrepant outcome. It is also possible that only one player experiences the short end; or discrepant outcomes may have been totally absent.

D-1. Some indicators of cooperativeness in early play. First let us consider each token turned from white to blue, from missile to factory, during any block of five trials of the game, to be a cumulative index of the cooperation achieved by that pair: i.e., the greater the number turned, the more the cooperation. Then, separating the Doves, Hawks, and Mugwumps according to their eventual performance as before, we find some very early differentiation between groups. During the first five trials the average Dove converted 8.5 tokens per game, the average Hawk 4.8 tokens, and the average Mugwump 4.2. (The Hawk-Mugwump difference is not statistically significant.) Fuller data are shown in Table 7.

The amount of cooperation for each of the three criterion groups may be calculated for every block of five nonoverlapping trials, as shown in Figure 2.

The Dove group clearly retains its dis-

TABLE 6

The Effect of Abstractness on Formation of Chiterion Groups

\begin{tabular}{|c|c|c|c|c|}
\hline & Doves & Hawks & Mugwumps & \\
\hline$\overline{\text { Abstract }\left(A_{1} \& A_{2}\right)}$ & $40.6 \%(13)$ & $28.1 \%(9)$ & $31.2 \%(10)$ & 32 \\
\hline \multirow[t]{2}{*}{ Simulated $\left(S_{1} \& S_{2}\right)$} & $40.6 \quad(13)$ & 25.0 & $34.4 \quad(11)$ & 32 \\
\hline & $31.2 \quad(26)$ & $26.5 \quad(17)$ & $32.8 \quad(21)$ & 64 \\
\hline
\end{tabular}

$\chi^{2}: 0.11 ;$ NS (df: 2). 
TABLE 7

Cooperativeness in Early Games

\begin{tabular}{lccccc}
\hline \hline Games & Doves & Hawks & $\begin{array}{c}\text { Mug- } \\
\text { wumps }\end{array}$ & $F_{2} / 637$ & p \\
\hline $1-5$ & 8.5 & 4.8 & 4.2 & 26.66 & $<0.05$ \\
$6-10$ & 9.3 & 3.3 & 5.1 & 35.76 & $<0.05$ \\
\hline
\end{tabular}

tinctiveness from the others. The Hawk group establishes itself below the Mugwumps on the seventh trial and remains there through all remaining trials. In sum, then, our findings show that Doves start higher on the cooperativeness index and ascend rapidly. Hawks start lower and decline, while Mugwumps start lower and ascend slowly.

The very fact that lock-ins (of Dove-like cooperation or Hawk-like defection) do occur suggests a degree to which partners come to play like each other. But how alike were partners during the first five games? Some insight into this question is given by calculating the performance of Dove members from each Dove pair who cooperated less than their partners. Average cooperation for the more niggardly Doves was 6.6 tokens per games (first five games). This still exceeds the average Hawk player's 4.8 tokens and even exceeds the average of the more cooperative member of each Hawk pair, which was 5.6 tokens.

The finding suggests that the relatively high level of early cooperation by those who later proved themselves to be Doves was not the result of a single player extending himself unilaterally. However, other findings reopen the question. If we examine the case in which one and only one player converted more than 50 percent of his tokens from white to blue (disarmament), we find that 10 out of 26 Dove pairs met this criterion over the first five games. Meanwhile, only two out of 17 Hawk pairs and two out of 21 Mugwump pairs showed one and only

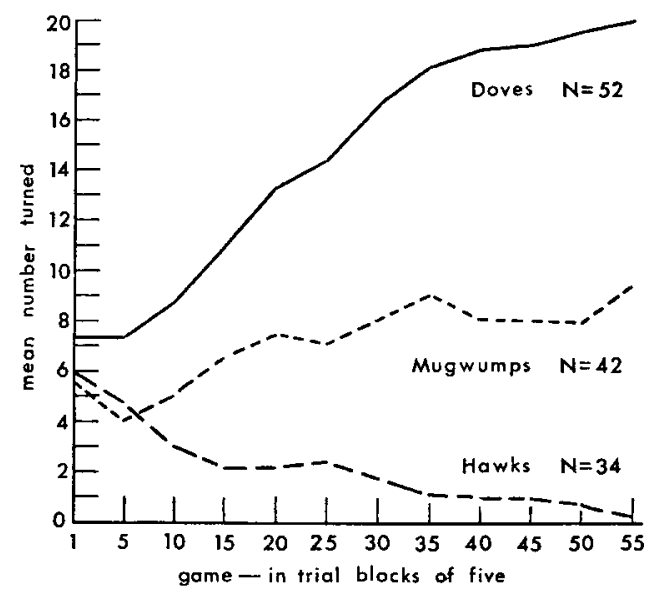

FIG. 2. Comparison of time courses of cooperative moves between three criterion groups distinguished by pair performances on the last five trials.

one member cooperating more than halfway.

Again, if we examine the instances in which a disparity of 25 or more tokens (an average of five tokens or more per game) occurred over the first five games, the same pattern emerges. Seven out of 26 Dove pairs showed this disparity. However, only two out of 17 Hawk pairs and three out of 21 Mugwump pairs showed this disparity. Obviously this does not resolve the case for or against the usefulness of early unilateral efforts in predicting ultimate criterion groups. But it does suggest the need for a finer analysis of game-by-game play, and such an analysis follows.

D-2. Early cooperative gestures as predictors of terminal pair performances. The data on cooperative gestures, converting 10 or more of one's white or weapon tokens to blue, are given in Figures 3 through 5 .

Certain patterns emerge. First, if a pair had even a single early experience of mutual cooperation, i.e., both making cooperative gestures on the same trial, that pair was likely to become a Dove pair.

Second, we observe that instances of 


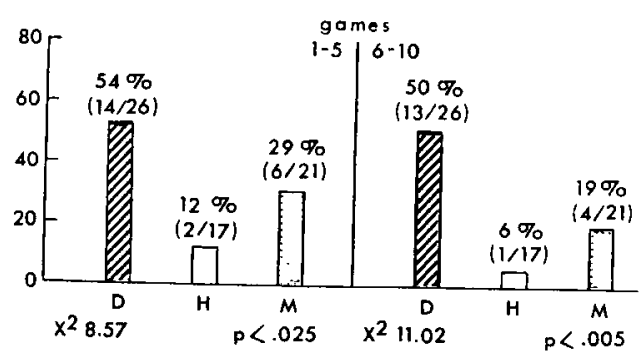

Fig. 3. Percentage of pairs showing at least one mutual cooperative gesture. D: Doves; H: Hawks; M: Mugwumps.

simultaneous gestures of cooperation were relatively infrequent during early play. The occurrence of unilateral gestures was more frequent among each of the three criterion groups.

Third, few of the Mugwump pairs were making cooperative gestures during the first five trials. The situation changed in the second five trials. Here numerous Mugwump pairs showed such gestures. Butas may be seen in Table 8-the gestures were not made simultaneously and, in fact, they tended to be made by only one player during the entire block of trials. By contrast, individual Hawks extended unilateral gestures of cooperation more often in the very first five trials. But, faced with nonreciprocation, these gestures became much less frequent in the second block of five trials. In sharp contrast, both members of

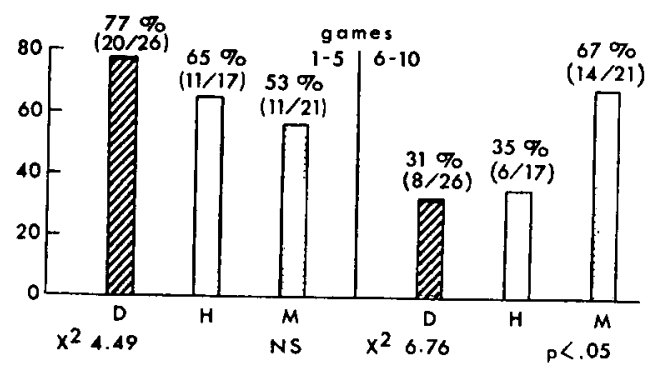

Fig. 4. Percentage of pairs showing at least one unilateral cooperative gesture.

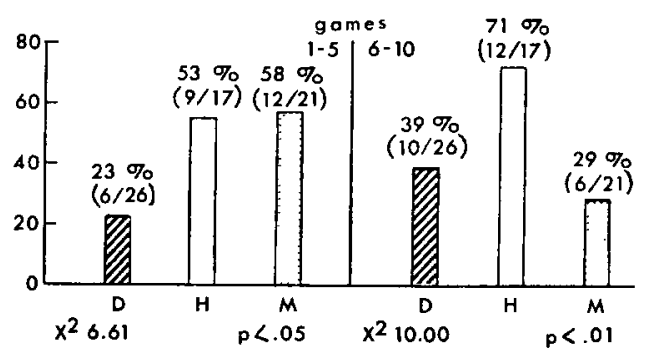

Fic. 5. Percentage of pairs showing (four or more) mutual noncooperative gestures. Use of four or more as an index reflects an approximate median split.

Dove pairs tended to extend gestures during early play. In fact, by the second block of five trials those Dove pairs which were not demonstrating cooperative gestures by both members were likely to be demonstrating few unilateral gestures either. Some Dove pairs apparently showed mutual willingness to cooperate from the start. The other Dove pairs were apparently more like the Hawks than like the Mugwumps in their early play. This can be seen also in Table 8, which shows that both Dove and Hawk groups increased their frequency of mutually noncooperative, armed gestures from the first to the second block of five trials, while Mugwumps reduced their frequency of mutual defection.

D-3. Early discrepant outcomes as predictors of terminal pair performance. A discrepant outcome, as noted earlier, means that one player has suffered and the other has benefited during a trial. What does such an experience do to the pair's future? Discrepant outcomes occurred in almost all pairs. Figure 6 compares the instances in which such outcomes were repeated (occurred at least twice within a block of five trials).

During the first five trials, significantly more Doves than Hawks or Mugwumps experienced two or more discrepant outcomes. However, by the second block of five 
TABLE 8

Effect of Rectprocation of Cooperative Gestures on Formation of Criterion Groups

\begin{tabular}{|c|c|c|c|c|}
\hline & \multicolumn{3}{|c|}{ Production of Cooperative Gestures } & \\
\hline & $\begin{array}{l}\text { Simultaneous } \\
\text { and mutual }\end{array}$ & Unilateral & None & \\
\hline \multicolumn{5}{|c|}{ Games 1-5 } \\
\hline Doves & $66 \%(17)$ & $23 \%(6)$ & $12 \%(3)$ & 26 \\
\hline Hawks & $12 \quad(2)$ & $65 \quad(11)$ & $24 \quad(4)$ & 17 \\
\hline \multirow[t]{2}{*}{ Mugwumps } & $29 \quad \underline{(6)}$ & $29 \quad(6)$ & $43 \quad(9)$ & 21 \\
\hline & $32.5(25)$ & $32.5(23)$ & $25 \quad(16)$ & 64 \\
\hline \multicolumn{5}{|c|}{ Games 6-10 } \\
\hline Doves & $54 \%(14)$ & $8 \% \quad(2)$ & $34 \%(10)$ & 26 \\
\hline Hawks & (2) & $12 \quad(2)$ & $77 \quad(13)$ & 17 \\
\hline \multirow[t]{2}{*}{ Mugwumps } & (6) & $43 \quad(9)$ & (6) & 21 \\
\hline & $35 \quad(22)$ & $20 \quad(13)$ & $45 \quad(29)$ & 64 \\
\hline
\end{tabular}

NoTE: Figures given are for the occurrence of a single incident. None $=$ mutual non-cooperative or armed gesture.

trials the Dove pairs were performing most congruently, showing fewest discrepant outcomes. Only the Mugwumps increased their frequency of discrepant outcomes during trials six through ten. This finding lends support to a conjecture introduced earlierthat even before the lock-in occurs, Dove and Hawk pairs tend to be moving toward greater symmetry (or sensitivity) in play than is true for the Mugwumps.

Figure 6 does not indicate whether the repeated occurrences of discrepant outcomes always favored the same player or whether both players had the experience of being

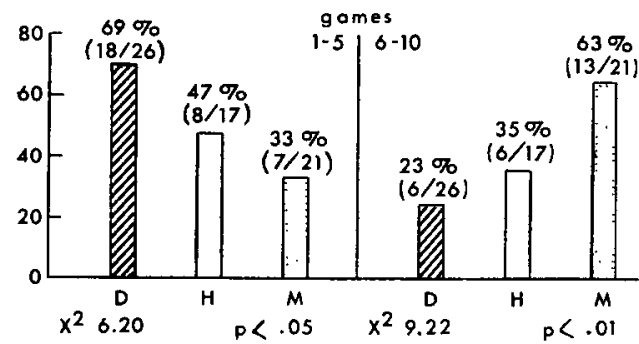

Fic. 6. Percentage of pairs showing repeated (two or more) discrepant outcomes. both victor and vanquished. Table 9 contrasts relative frequencies with which the discrepant experiences were reciprocal, unidirectional, or entirely absent for the three criterion groups.

During the first five games, only the Dove pairs showed a high frequency of cases in which both players experienced the discrepancy from both directions. By the second block of five trials, the Doves and the Hawks showed the greatest number of pairs with no discrepant outcomes at all. The Mugwump pairs were still showing discrepancies during those trials. The data suggest that early experience of the good (and bad) effects of incongruent performance is an indication of future Dove-like cooperation-if each player has had a taste of the medicine of being caught disarmed and an opportunity of seeing the other player cooperate more than himself.

\section{Discussion and Conclusions}

The terminal states of Dove, Hawk, and Mugwump may be viewed as products of 
TABLE 9

Reciprocation of Discrepant Outcomes and the Formation of Cruterion Groups

\begin{tabular}{|c|c|c|c|c|}
\hline & \multicolumn{3}{|c|}{ Production of Discrepant Outcomes } & \\
\hline & Reciprocal & Unidirectional & None & \\
\hline \multicolumn{5}{|c|}{ Games 1-5 } \\
\hline Doves & $42 \%(11)$ & $50 \%(13)$ & $8 \% \quad(2)$ & 26 \\
\hline Hawks & $6 \quad(1)$ & $71 \quad(12)$ & $23 \quad$ (4) & 17 \\
\hline \multirow[t]{2}{*}{ Mugwumps } & $14 \quad(3)$ & $53 \quad(11)$ & (7) & 21 \\
\hline & $24 \quad(15)$ & $56 \quad(36)$ & $20 \quad(13)$ & 64 \\
\hline \multicolumn{5}{|c|}{$\chi^{2}: 11.69 ; \mathrm{p}<0.025$} \\
\hline \multicolumn{5}{|c|}{ Games 6-10 } \\
\hline Doves & $62 \%(16)$ & $31 \% \quad(8)$ & $8 \%$ (2) & 26 \\
\hline Hawks & $12 \quad(2)$ & $71 \quad(12)$ & (3) & 17 \\
\hline \multirow[t]{2}{*}{ Mugwumps } & $43 \quad(9)$ & $38 \quad(8)$ & (4) & 21 \\
\hline & $\overline{42} \quad \overline{(27)}$ & $\begin{array}{ll}-\overline{44} & \overline{(28)}\end{array}$ & $\begin{array}{ll}- & \\
14 & (9)\end{array}$ & $\overline{64}$ \\
\hline \multicolumn{5}{|c|}{$\chi^{2}: 6.87 ; \mathrm{p}<0.10$} \\
\hline
\end{tabular}

the forces that bring individuals into social units which are either cohesive and facilitative, or divisive and despairing, or uncertain and unstable. Evidence from this experiment suggests that the locus of these forces lies primarily in the circumstances of the interaction rather than in such characteristics as personality traits brought to the situation. In addition, the early trials of interaction, like the early years, may have enduring effects upon later behavior.

From analysis of early interaction it seems clear that the interaction pattern which induces mutual cooperation is a two-party affair. For lasting cooperation, parties to a conflict situation do have to make overtures, for that is -in the last analysis - all they can do. But what also seems necessary is that cooperative gestures of the other are met with similar responses on one's own part at early stages in the conflict process.

Gestures of cooperation, whether or not they are defined as we have done here, are clearly both causes and effects of game per- formance. Our examination of the result of natural game conditions indicates that a unilateral initiative toward cooperation, if not quickly reciprocated (i.e., if it remains unilateral), does not lead to the development of a cooperative pair. On the other hand someone must initiate cooperative play, and it is relatively rare, in the absence of overt communication, that both players do this simultaneously. The findings on cooperative gestures (Table 8 ) and discrepant outcomes (Table 9) suggest that both unilateral and reciprocal elements are important in game performance. Their relative importance, however, would seem to be most readily determinable in a more structured experimental situation with stooges or a false feedback procedure.

At some point in the sequential moves and countermoves of a conflict situation it seems likely that a person takes cognizance of the intent which the other player is trying to communicate (or perhaps communicating without trying) through his moves. One 
subject, for example, offered the following comment after the experiment: "At first I thought he [the other player] was stupid letting me win like that. But after a while I saw that he was trying to get me to turn over more factories so we could both win." Obviously, there was a cost involved here in the signaling of intent. The authors are currently working on a modification of the game which permits signals of intention, in the form of inspections, without cost to either player.

The realization that behavior can be used to communicate one's hopes and expectations and threats to the other player raises the contest from what may be viewed initially as a game against nature, a game in which the other's moves are only partly predictable and wholly out of reach of one's influence. A second realization, however, seems even more critical for enduring cooperation in a pair. It is the experience that both oneself and the other party are really part of the same system, unified by a common fate, and no longer independent decision-makers. Viewed from this perspective, the game does have a rational or strategic resolution which is easily found: cooperate fully on every trial. We have numerous instances of such comments as: "I could see from the start that turning them all over was the only thing for us to do." This perception of "we" or "us" is clearest if we look at some comments of Dove pairs whose cooperation came late and who played more like Hawks at the beginning. "I could see at this point that we were both in a rut and weren't going anyplace." The data we have showing more frequent early instances of mutual cooperative gestures by Dove pairs or more frequent reversing of roles in the case of discrepant outcomes suggest the very conditions which might teach the lesson of interdependence and common destiny.
Why a pair of potential antagonists seems better able to learn this during an early run of protracted decision games (long games) than during an equivalent run of short games is not entirely clear. At this point, our best guess seems to be that slowing the pace of the decision process, before the pattern of play has settled, enhances the opportunity for players to recast their concept of the conflict situation. Such cognitive recasting could then produce the realization that (1) communication through behavior is occurring, or (2) the two parties are really part of the same system, or both. From among five individual difference measures, only mutual tolerance for ambiguity seemed relevant to arriving at mutual cooperation. The ability to reframe old perceptions is a part of tolerance for ambiguity. The finding would seem consistent with the conclusion that a cognitive recasting which occurs during the moves and countermoves of an interpersonal conflict is necessary for the self-organization of the two parties into a single cohesive unit.

The most remarkable thing about the Hawks as a group is that they hardly ever tried to cooperate. Following a few unilateral and unreciprocated gestures at the very beginning, the frequency of cooperative gestures (either unilateral or reciprocal) becomes so low that one might conclude that one reason why Hawks never learned to cooperate is because they never experimented with or explored the communication channels that the game was structured to provide. One cannot say of them, as a group, that they are more deceitful or treacherous or aggressively competitive players. On the basis of game performance, what stands out is their conservatism, caution, and reluctance to try a new approach. This observation is also supported by the fact that the one per- 
sonality indicator that did predict to game outcomes was tolerance for ambiguity. Players who were less tolerant of ambiguity seemed unwilling to explore the various potentials in the game situation.

In contrast, the Doves as a group were experimenting with cooperation from the start. Some tried and succeeded early, others failed but tried again later and were successful. Some of them use, and some of them report, interesting strategies of rewards and punishments intended to lure the other player toward mutual trust. The description of such strategies and the search for their determinants and their consequences make an intriguing problem for future research.

The Mugwump pairs probably represent several entities. Some may have contained a member who never changed his initial perception that success in the game depended solely upon outsmarting one's partner. Others may have rejected the formation of a predictable social unit because of fascination with gamesmanship-much like the Don Juans who enjoy the hunt but cannot stay with the marriage. One might argue that all individuals faced with sustained interaction do eventually develop stable and reciprocal behavior patterns-but our experiments were continued through only 55 trials.

We have stressed in our conclusions the theme that reciprocal behaviors at an early stage of the interaction process are of major importance in the development of later trust, and that personality indicators seem less relevant. Two alternative theories are brought to the fore by this. The first says that circumstances of play alone determine the resolution of conflict. By chance, this theory would state, certain moves made by one party meet moves made by the other, and the distribution of these random pairings provides the starting point for stochastic processes (probabilities of performance contingent on the prior happenings) which lead to the final outcomes.

The alternate theory is not that the player's cooperation is a product of some inherent propensity, a personal proclivity which he carries about either to cooperate or not. The extremely high correlation of cooperation rates found between randomly matched pair members seems adquate for rejection of such a theory. But the alternative to the randomstart, stochastic-interaction theory is the view that players do bring to the game setting certain proclivities, not to act in a certain way, but rather to react in certain ways to the contingent circumstances presented by the other player's behavior. To test this latter theory one will have to think of personality traits as contingent reaction propensities; measure these propensities; and study their effects upon experimentally arranged contingencies of opponent's behavior. This is an important task for future research. What our present research has done is to help crystallize these alternative theories regarding the ways in which interaction synthesizes individuals into social units.

\section{REFERENCES}

Atrinson, J. W., and A. C. Raphelson. "Individual Differences in Motivation and Behavior in Particular Situations," Journal of Personality, 24 (1956), 349-63.

BERGER, E. M. "The Relation between Expressed Acceptance of Self and Expressed Acceptance of Others," Journal of Abnormal and Social Psychology, 47 (1952), 778-83.

Brxenstine, V. E., N. Chambers, H. Potash, and D. V. Wrison. "Effects of Asymmetry in Payoff on Behavior," Journal of Abnormal and Social Psychology, 67 (1963), 308-13.

Bexenstine, V. E., H. M. Potash, and D. V. Wusson. "Effects of Cooperative Choice by Other Player on Choices in a Prisoner's Dilemma Game." Manuscript. Nebraska Psychiatric Institute, 1961.

Davis, R. H., P. B. Carpenter, and C. W. 
Mrssler. A Game for Studying the Problems of Arms Control. Santa Monica, Calif.: Systems Development Corporation, AP-779, 1962.

Deursch, M. "Trust and Suspicion," Joumal of Conflict Resolution, 2, 4 (Dec. 1958), 265-79.

- "The Effect of Motivational Orientation upon Threat and Suspicion," Human Relations, 13 (1960a), 123-39.

- "Trust, Trustworthiness, and the F Scale," Journal of Abnormal and Social Psychology, 61 (1960b), 138-40.

EDwards, W., and P. SLovic. "Information Seeking to Reduce the Risk of Decisions." Paper presented at Midwestern Psychological Association, Chicago, May 1962.

Flood, M. M. "Some Experimental Games," Management Science, 5 (1958), 5-26.

Guetzxow, H. "A Use of Simulation in the Study of Inter-Nation Relations," Behavioral Science, 3 (1957), 183-91.

Kogan, N., and M. A. Wallach. "The Effect of Anxiety on Relations Between Subjective Age and Caution in an Older Sample." In P. H. Hoch and J. Zurin (eds.), Psychopathology of Aging. New York: Grune and Stratton, 1961.

Levinson, D. J. "Authoritarian Personality and Foreign Policy," Journal of Conflict Resolution, 1, 1 (Mar. 1957), 37-57.

Looms, J. L. "Communication, the Development of Trust and Cooperative Behavior," Human Relations, 12 (1959), 305-15.

LuCE, R. D., and H. RAIFFA. Games and Decisions. New York: Wiley, 1957.

LUTZKER, D. "Internationalism as a Predictor of Cooperative Game Behavior," Journal of Conflict Resolution, 4, 4 (Dec. 1960), 42635.

Marlowe, D. "Psychological Needs and Performance in a Two-Person Non-Zero-Sum Game." Paper read at Eastern Psychological Association, Atlantic City, April 1962.

Martin, Niles W., Jr. "Some Effects of Communication of Group Behavior in Prisoner's Dilemma." Unpublished Ph.D. thesis, Case Institute of Technology, 1964.

McClintock, C. G., A. A. Harrison, S. Strand, and P. Gallo. "Internationalism, Isolationism, Strategy of the Other Player and Two Person Game Behavior," Journal of
Abnormal and Social Psychology, 67 (1963), 631-36.

Minas, J. S., A. Scodet, D. Marlowe, and H. Rawson. "Some Descriptive Aspects of Two-Person, Non-Zero-Sum Games," Journal of Conflict Resolution, 4, 2 (June 1960), 193-97.

O'Connor, Patrucia. "Intolerance for Ambiguity and Abstract Reasoning Ability," Journal of Abnormal and Social Psychology, 47 ( 1952 ), Supplement.

Osgood, Charles E. "Suggestions for Winning the Real War with Communism," Journal of Conflict Resolution, 3, 4 (Dec. 1959), 295325.

Pilisuk, M., and A. Rapoport. "A Non-ZeroSum Game Model of Some Disarmament Problems." Paper given at Peace Research Conference, University of Chicago, November 1963 .

—_ - - "Stepwise Disarmament and Sudden Destruction in a Two-Person Game," Journal of Conflict Resolution, 8, 1 (Mar. 1964), 36-49.

QuaNT, Richard E. "On the Use of Game Models in Theories of International Relations." In K. KNOrR and S. VeraA (eds.), The International System. Princeton, N.J.: Princeton University Press, 1961, 9-76.

RAPOPORT, A. Fights, Games, and Debates. Ann Arbor, Mich.: University of Michigan Press, 1960.

- "The Use and Misuse of Game Theory," Scientific American, 6 (1962), 108-18.

- "Tacit Communication in Experiments in Conflict and Cooperation," International Psychiatry Clinics, 1 (1964a), 225-44.

- Strategy and Conscience. New York: Harper, 1964b.

- Prisoner's Dilemma. Ann Arbor, Mich.: University of Michigan Press, 1965. and C. Orwant. "Experimental Games: A Review," Behavioral Science, 7, (1962), 1-37.

Rogers, C., and Rosalind Dymond. Psychotherapy and Personality Change. Chicago: University of Chicago Press, 1954.

SAATY, T. L. "A Model for the Control of Arms," Operations Research, 12, 4 (JulyAug. 1964).

Sampson, P. L., and H. P. Smrtre. "A Scale to Measure World-Mindedness Attitudes," 
Journal of Social Psychology, 45 (1957), 99 106.

Schelling, Thomas C. "Experimental Games and Bargaining Theory." In K. KNore and S. Verba (eds.), The International System. Princeton, N.J.: Princeton University Press, 1961, 47-68.

- The Strategy of Conflict. Cambridge, Mass.: Harvard University Press, 1960.

ScODEL, A. "Induced Collaboration in Some Non-Zero-Sum Games," Journal of Conflict Resolution, 6, 4 (Dec. 1962), 335-40.

, J. S. Minas, P. Ratoosh, and M. LIPETZ. "Some Descriptive Aspects of TwoPerson, Non-Zero-Sum Games," Journal of
Conflict Resolution, 3, 2 (June 1959), 11419.

Solomon, L. "The Influence of Some Types of Power Relationships and Game Strategies on the Development of Interpersonal Trust," Journal of Abnormal and Social Psychology, 61 (1960), 223-30.

Thibaut, J. W., and H. H. Kelley. The Social Psychology of Groups. New York: Wiley, 1959.

Werster, H., N. Sanford, and M. Freedman. "A New Instrument for Studying Authoritarianism," Journal of Psychology, 40 (1955), 73-84. 